\title{
Piriprost: A Putative Leukotriene Synthesis Inhibitor Increases Pulmonary Blood Flow in Fetal Lambs
}

\author{
JEROME LEBIDOIS, SCOTT J. SOIFER, RONALD I. CLYMAN, AND MICHAEL A. HEYMANN \\ Cardiovascular Research Institute and Departments of Pediatrics, Phvsiology, Obstetrics, Gynecology, and \\ Reproductive Sciences, University of California San Francisco, and Department of Pediatrics, Mount Zion \\ Hospital and Medical Center, San Francisco, California 94143
}

\begin{abstract}
Leukotrienes may control fetal pulmonary vascular tone since infusions of putative leukotriene receptor antagonists markedly increase pulmonary blood flow and decrease pulmonary vascular resistance in fetal lambs. This hypothesis would be strengthened if inhibition of leukotriene synthesis also produced similar hemodynamic changes. We therefore studied the effects of piriprost ( $U$ 60257), a putative leukotriene synthesis inhibitor, on thirteen fetal lambs at 137 to 140 days gestation. In preliminary studies in four fetal lambs, doses of $U \mathbf{6 0 2 5 7}$ greater than $20 \mathrm{mg} / \mathrm{kg}$ increased pulmonary blood flow. In the nine other fetal lambs, U $60257(31.7 \pm 4.1 \mathrm{mg} / \mathrm{kg})$ increased pulmonary blood flow by $502 \%(p<0.05)$ and decreased pulmonary vascular resistance by $87 \%(p<0.05)$. Pulmonary arterial and left atrial pressures were unchanged. Descending aortic pressure was increased $(p<0.05)$ and heart rate was decreased $(p<0.05)$. The abilities of both putative leukotriene synthesis inhibitors and leukotriene receptor antagonists to similarly increase fetal pulmonary blood flow and decrease pulmonary vascular resistance are consistent with the hypothesis that leukotrienes play a role in regulating fetal pulmonary vascular tone. (Pediatr Res 22: $350-354,1987$ )
\end{abstract}

\section{Abbreviation}

$\mathrm{SaO}_{2}$, hemoglobin oxygen saturation

In the fetus, pulmonary blood flow is low, representing less than $10 \%$ of combined ventricular output. This low pulmonary blood flow is maintained by a high pulmonary vascular resistance (1). During the early part of gestation, the high pulmonary vascular resistance is likely maintained by the small cross-sectional area of the pulmonary vascular bed. During the latter part of gestation, the high pulmonary vascular resistance is likely maintained in part by active vasoconstriction of the muscularized small pulmonary arteries $(1-3)$. The mechanisms involved in this vasoconstriction remain to be fully explored.

Leukotrienes $\mathrm{C}_{4}$ and $\mathrm{D}_{4}$, products of $5^{\prime}$-lipoxygenase pathway of arachidonic acid metabolism, induce pulmonary vasoconstriction in various species (4-8). They also may play a role in the development of hypoxic pulmonary hypertension (9-14). We have investigated the role of leukotrienes in the control of high

Received February 9, 1987: accepted April 22, 1987.

Requests for reprints and correspondence Scott J. Soifer, M.D., M-643, University of California, San Francisco, CA 94143-0106.

Supported in part by HL 35518 and U.S. Public Health Service Program Project Grant HL 24056 from the NHLBI. pulmonary vascular resistance and low pulmonary blood flow in fetal lambs. Infusions of putative leukotriene receptor antagonists (FPL 55712 and FPL 57231, Fisons, plc Loughborough, UK) increased pulmonary blood flow (3). This increase was similar in magnitude to the 8 - to 10 -fold increase in pulmonary blood flow occurring spontaneously with ventilation at birth (1). We concluded that leukotrienes may regulate pulmonary vascular resistance in the fetus. However, the hemodynamic effects produced by these leukotriene receptor antagonists may have been caused by nonspecific effects of these compounds. Our hypothesis that leukotrienes are involved in maintaining the pulmonary vascular resistance in the fetus would be strengthened if inhibition of leukotriene synthesis also produced similar hemodynamic changes. Therefore, we studied whether piriprost (U 60257, Upjohn Co., Kalamazoo, MI), a putative leukotriene synthesis inhibitor, produces a similar increase in pulmonary blood flow and decrease in pulmonary vascular resistance in fetal lambs. We also studied whether these changes are associated with alterations in the distribution of combined ventricular output.

\section{METHODS}

Thirteen pregnant ewes were operated on at 133 to 136 days of gestation under epidural anesthesia with $2 \%$ pontocaine hydrochloride and intermittent sedation with ketamine hydrochloride ( 1 to $2 \mathrm{mg} / \mathrm{kg}$ intravenous every $15-30 \mathrm{~min}$ ). Polyvinyl catheters were placed in a maternal hind limb artery and vein. The uterus was exposed through a midline abdominal incision. Through a small uterine incision, a fetal hind limb was exteriorized. Fetal surgery was performed under local anesthesia with $0.5 \%$ lidocaine hydrochloride. We inserted polyvinyl catheters into the descending aorta through the pedal artery and into the inferior vena cava through the pedal vein. To prevent fetal movement, succinylcholine chloride was administered intravenously.

After closure of the first uterine incision, a second uterine incision was made to expose the fetal chest. A left lateral thoracotomy was performed in the third or fourth intercostal space. Polyvinyl catheters were inserted into the internal thoracic artery and vein and advanced to the ascending aorta and superior vena cava, respectively. The pericardium was then opened along the pulmonary trunk. Teflon cannulae connected to polyvinyl catheters were inserted into the left atrium, the pulmonary trunk (proximal to the main pulmonary artery-ductus arteriosus bifurcation), and the main pulmonary artery. A large bore polyvinyl catheter was inserted into the amniotic cavity. The chest and uterine incisions were closed. Amniotic fluid losses were replaced with warm $0.9 \%$ saline. All the catheters were brought to a pouch sewn to the ewe's flank, filled with heparin, and plugged. The maternal abdomen was closed in layers. On the day of surgery 
and each day thereafter, the ewe received one million $U$ of Penicillin (; and $400 \mathrm{mg}$ of Kanamycin sulfate intravenously. Antibiotics were also placed into the amniotic cavity. Two to 4 days were allowed for recovery.

Drug preparation. Piriprost. U 60257 (Upjohn (o. Kalamazoo. MI). was stored at $-20^{\circ}$ (' and prepared immediately prior to each experiment by diluting the compound in $5 \mathrm{ml}$ of $0.9 \%$ saline.

Measurements and calculations. Pulmonary arterial. descending aortic, left atrial, and amniotic cavity pressures were measured with Statham P23db pressure transducers and recorded continuously on a Beckman multichannel direct writing recorder. Mean pressures were obtained by electrical integration. Amniotic cavity pressure was used as a zero reference for fetal vascular pressures. Heart rate was measured with a cardiotachometer triggered by the deseending aortic pressure wave.

Blood flows were measured by the microsphere method $(15$. 16). Pulmonary blood flow was measured by the inferior vena caval injection of $15-\mu$ diameter radionuclide-labeled microspheres with a reference sample withdrawn continuously from the pulmonary trunk. Pulmonary blood flow is expressed as ml. min 100 g lung tissue! Combined ventricular output and specific organ blood flows were measured by the inferior vena caval injection of $15-\mu$ diameter radionuclide-labeled microspheres with reference samples withdrawn continuously from the pulmonary trunk, the descending aorta. and the ascending aorta. This method allows calculation of flow to the lungs. fower hody organs, and upper body organs. The sum of the organ blood flows is the combined ventricular output. Organ blood flows are expressed as mlmin '. 100 g tissue '. If U 60257 increased pulmonary blood flow, pulmonary venous return and left atrial pressure would also have increased. This may have decreased the physiologie right to left shunt through the foramen ovale. If this had occurred. then the number of microspheres in the upper body organs might have been too low for accurate blood flow calculations. Therefore. we also injected $15-\mu$ diameter radionuclide-labeled microspheres into the left atrium, simultaneously with the inferior vena caval injection. for more accurate upper body blood flow measurements.

Pulmonary vascular resistance was calculated as the difference between the pulmonary arterial mean pressure and the left atrial mean pressure. divided by the pulmonary blood flow.

Fetal descending aortic blood gases and pH were measured at

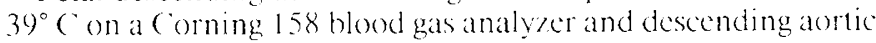
hemoglobin oxygen saturation was measured on a Radiometer OSM2 Hemoximeter.

Experimental protecol. The 1.3 fetal lambs were studied at 1.37 10 140) days gestation (3 10 4 days after surgery). The study was performed while the ewe was standing quietly in a study cart after a 1-h period to adjust to the laboratory. Preliminary studies were performed on four fetal lambs to determine the dose of $U$ 60257 that would produce a large increase in pulmonary blood flow. Ioses of $1,3,5,20$, and $30 \mathrm{mg} / \mathrm{kg}$ estimated fetal weight were used. Two control measurements of pulmonary arterial. descending aortic and left atrial pressures. heart rate pulmonary blood flow. and descending arrtic blood gases, pH. and SaO were made 60 min apart. All blood withdrawn was replaced with an equal volume of fresh heparinized donor fetal or maternal blood. $A$ dose of $\cup 60257$, randomly selected (using a table of random numbers) from the above doses. was injected for 5 min into the main pulmonary artery. Repeat measurements of the hemodynamic variables, pulmonary blood flow and descending aortic blood gases. pll. and $\mathrm{SaO}$, were made 15 and 3() $\mathrm{min}$ after the injection. Sixty min later, repeat measurements of the hemodynamic variables. pulmonary blood flow and descending aortic blood gases, pHl and SaO , were made. Another random dose of If 6(0)257 was then injected into the main pulmonary artery Repeat measurements were made 1.5 and 30 min after the second injection. (One fetal lamb received three random doses of I 60257.
Based on these data, we selected a dose of approximately 30 $\mathrm{mg} / \mathrm{kg}$ estimated fetal weight to evaluate the hemodynamic effects of leukotriene synthesis inhibition. In the remaining nine fetal lambs. two control measurements of pulmonary arterial. descending aortic and left atrial pressures, heart rate. pulmonary blood flow, and descending aortic blood gases. pht and $\operatorname{sal}$ ). were made 60 min apart. The second measurement was made 5 min prior to the injection of the $1: 60257$ (control). In seren of these nine fetal lambs. combined ventricular output and specific organ blood tlows also were measured immediately prior to l 60257 injection. $60.257(31.7 \pm 4.1 \mathrm{mg} / \mathrm{kg})$ was then injected for $5 \mathrm{~min}$ into the main pulmonary artery. The hemodynamic variables, pulmonary blood tlow, descending andic blood gases. pH, and $\mathrm{Sa}()$, were measured again $15,30,60,120$. and 180 min alter starting the injection. (ombined ventricular output and specifie organ blood flows were measured again 30 min alter the injection.

At the end of the experiment. the cwe and the fotus were killed with an overdose of pentobarbital. All catheter positions were confirmed. The autopsied fetus was weighed and the organs and reference samples prepared for microsphere analysis (1 16 . 16).

Statistical analisis. for the nine lambs who had complete studies, the two control measurements were averaged. The means \pm SD were calculated for pulmonary arterial. deseending arortic. and left atrial pressures heart rate pulmonary blood flow. pulmonary vascular resistance, and descending aortic blood gases. pH, and $S_{a}(O)$, during the control period. $15,30.60 .12(0$. and $180 \mathrm{~min}$ after the injection of $160(2) 57$. Differences in these variables between time periods were determined by the friedman test (nomparametric analysis of variance) with multiple comparison testing (17). The means \pm SD were calculated for combined ventricular output and specific organ blood flows during the control period and 30 min after injection of $46(1) 257$ and compared by the Wikoxen paired sample test (18). A $/ 2<0.05$ was considered statistically significant.

\section{RISLITS}

The 13 fetal lambs weighed $3.60 \pm 0.49 \mathrm{~kg}$ and their lungs weighed $90.94 \pm 19.44 \mathrm{~g}$. In the preliminary studies, in four fetal lambs, intrapulmonary injections of 1160257 (more than 20) $\mathrm{mg} /$ $\mathrm{kg}$ ) increased pumonary blood flow. In the nine other fetal lambs. $\mathrm{i}$ 6(0)257 (31.7 $\pm 4.1 \mathrm{mg} / \mathrm{kg})$ increased pulmonary blocd flow by $400 \% 30$ min after the injection $(p<0.05)$ (1)ig. 1). The maximum pulmonary blood flow occurred 15 min after the injection in two fetal lambs. 30 min after the injection in six fetal lambs. and 60 min after the injection in one fetal lamb. The maximum pulmonary blood flow was $825+494 \mathrm{ml} \cdot \mathrm{min} \cdot 1(00$ g lung tissue $\left.{ }^{\prime}(p)<0.05\right)$ which represented a $502 \%$ increase

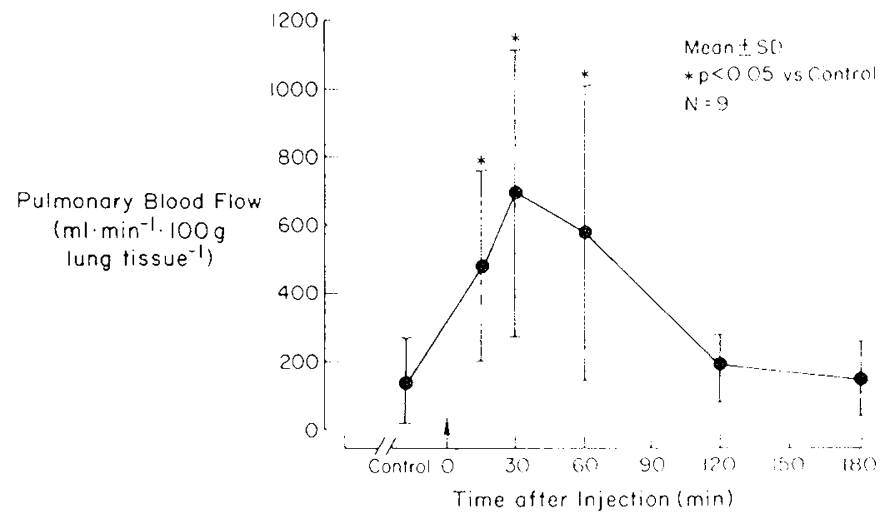

Fig. 1. The effects of an intrapulmonary injection of $1 ! 6(1) 257(31.7$ $\pm 4.1 \mathrm{mg} / \mathrm{kg}$ ) on pulmonary bood flow in late gestation fetal lambs. 
from control. Pulmonary blood flow returned to control levels $120 \mathrm{~min}$ after the injection. U 60257 decreased pulmonary vascular resistance by $84 \%$ from $0.69 \pm 0.41$ to $0.11 \pm 0.07 \mathrm{~mm}$ $\mathrm{Hg} \cdot \mathrm{ml}^{-1} \cdot \mathrm{min} \cdot 100 \mathrm{~g}$ lung tissue $30 \mathrm{~min}$ after the injection $(p<$ $0.05)$. The minimum pulmonary vascular resistance was $0.09 \pm$ $0.07 \mathrm{~mm} \mathrm{Hg} \cdot \mathrm{ml}^{-1} \cdot \mathrm{min} \cdot 100 \mathrm{~g}$ lung tissue, which represented a $87 \%$ decrease from control (Fig. 2). Pulmonary vascular resistance returned to control levels $120 \mathrm{~min}$ after the injection. Pulmonary arterial and left atrial pressures were unchanged (Table 1). Descending aortic pressure was slightly increased 15 and $60 \mathrm{~min}$ after the injection $(p<0.05)$. Heart rate decreased to less than 100 beats/min during and immediately after $U$ 60257 injection. This bradycardia lasted for $15 \mathrm{~min}$ after the injection $(p<0.05)$ (Table 1). There were no other consistent changes in vascular pressures for the first $15 \mathrm{~min}$ after the injection. These hemodynamic changes occurred despite the development of hypoxemia $15 \mathrm{~min}$ after the injection $(p<0.05)$ and acidosis 15 and $30 \mathrm{~min}$ after the injection $(p<0.05)$ (Table 1).

Combined ventricular output was unchanged by the injection of $\mathrm{U} 60257$. Myocardial blood flow was increased $(p<0.05)$ while brain and upper body carcass flows were decreased $(p<$ 0.05 ). Placental blood flow represented a lower percentage of combined ventricular output $(p<0.05)$ (Table 2).

\section{DISCUSSION}

The present study was performed to further investigate the role of leukotrienes in the control of pulmonary blood flow and pulmonary vascular resistance in fetal lambs. This study has shown that an intrapulmonary injection of piriprost (U 60257), a putative leukotriene synthesis inhibitor, significantly increases pulmonary blood flow and decreases pulmonary vascular resistance in late gestation fetal lambs. These changes were similar in

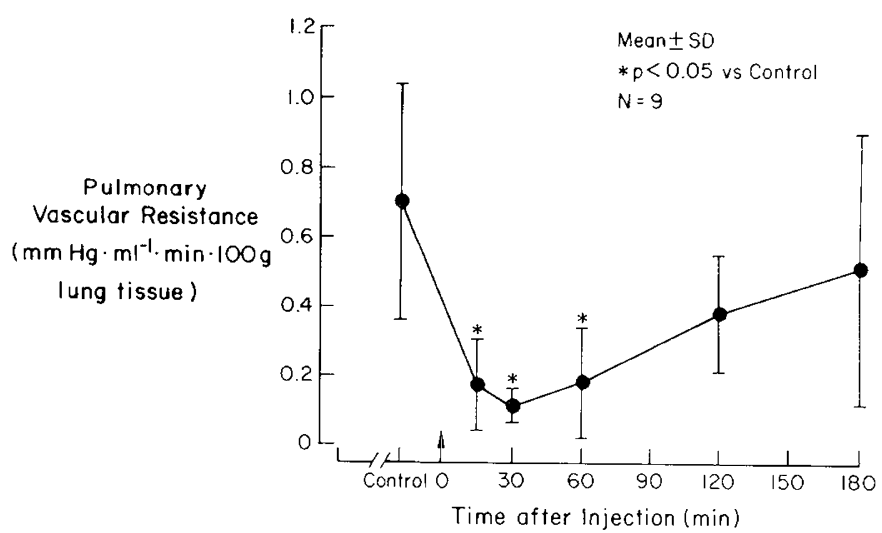

Fig. 2. The effects of an intrapulmonary injection of $\mathrm{U} 60257$ (31.7 $\pm 4.1 \mathrm{mg} / \mathrm{kg}$ ) on pulmonary vascular resistance in late gestation fetal lambs. magnitude to those that occur with the initiation of ventilation at birth (1). These changes were also similar in magnitude to those produced in late gestation fetal lambs by an intrapulmonary infusion of the leukotriene receptor antagonist FPL 57231, which increased pulmonary blood flow by $580 \%$ and decreased pulmonary vascular resistance by $87 \%$ (3). That structurally dissimilar compounds, one a putative leukotriene synthesis inhibitor and the other a putative leukotriene receptor antagonist, similarly increase pulmonary blood flow and decrease pulmonary vascular resistance, supports the hypothesis that leukotrienes play a role in controlling pulmonary vascular tone in the fetal lamb.

Several different mechanisms could be responsible for the observed increase in pulmonary blood flow. Constriction of the ductus arteriosus by U 60257 could produce an increase in pulmonary blood flow. However, this would be accompanied by an increase in pulmonary arterial pressure and in the pressure difference across the ductus arteriosus (19). This did not occur in these studies and descending aortic pressure increased, indicating little or no effect on or of the ductus arteriosus. An overall increase in combined ventricular output might also be accompanied by an increase in pulmonary blood flow. This did not occur in these studies. There was a redistribution of combined ventricular output to maintain specific organ blood flow. The percentage of combined ventricular output going to the carcass, kidney, and placenta decreased. These changes are similar to those seen during ventilation in the fetus after pulmonary blood flow increases (21). Myocardial blood flow increased since pulmonary venous return and left ventricular output increased. Brain blood flow also decreased, although the mechanism producing this change is unclear.

The decreases in arterial blood $\mathrm{PO}_{2}$ and $\mathrm{pH}$ occurring after the intrapulmonary injection of $U 60257$ are likely caused by the decrease in the proportion of combined ventricular output distributed to the placenta. Acidosis and hypoxemia have previously been shown to reduce pulmonary blood flow and, therefore, played no role and even may have opposed the changes we observed (20). It is more likely, therefore, that $U 60257$ had a more direct local effect on the pulmonary vasculature by inhibiting the production of leukotrienes which are known to be pulmonary vasoconstrictors.

Although U 60257 and FPL 57231 had similar effects on pulmonary blood flow and vascular resistance in late gestation fetal lambs, they had different effects on some of the other variables. Both compounds similarly decreased arterial $\mathrm{pH}$. U 60257 decreased heart rate and increased descending aortic pressure, while FPL 57231 increased heart rate and decreased pulmonary arterial and descending aortic pressures. U 60257 also decreased $\mathrm{PaO}_{2} 15$ min after the injection, while $\mathrm{PaO}_{2}$ was not measured after $15 \mathrm{~min}$ of the infusion of FPL 57231. These differences may be due to differences in the mode of administration (bolus injection versus continuous infusion) or to direct effects of the compounds themselves.

$\mathrm{U} 60257$ inhibits leukotriene synthesis by inhibiting both the $5^{\prime}$-lipoxygenase and $\mathrm{LTD}_{4}$ synthetase enzyme steps (22-26). U

Table 1. Effect of $U 60257$ on vascular pressures, heart rate, and descending aortic $p H$ and blood gases [mean $\pm S D(n=9)]$

\begin{tabular}{|c|c|c|c|c|c|c|}
\hline & Control & $15 \mathrm{~min}$ & $30 \mathrm{~min}$ & $60 \mathrm{~min}$ & $120 \mathrm{~min}$ & $180 \mathrm{~min}$ \\
\hline $\begin{array}{l}\text { Pulmonary arterial pressure (mm } \\
\mathrm{Hg} \text { ) }\end{array}$ & $54.0 \pm 4.1$ & $56.2 \pm 3.7$ & $57.3 \pm 5.2$ & $55.9 \pm 6.2$ & $58.6 \pm 4.8$ & $55.4 \pm 5.5$ \\
\hline $\begin{array}{l}\text { Descending aortic pressure (mm } \\
\mathrm{Hg})\end{array}$ & $50.9 \pm 2.5$ & $55.0 \pm 5.0^{*}$ & $54.4 \pm 5.2$ & $55.0 \pm 3.9^{*}$ & $55.1 \pm 8.2$ & $50.8 \pm 7.2$ \\
\hline Left atrial pressure $(\mathrm{mm} \mathrm{Hg})$ & $2.4 \pm 1.9$ & $3.1 \pm 2.0$ & $4.0 \pm 2.6$ & $4.9 \pm 2.3$ & $4.4 \pm 2.4$ & $4.1 \pm 2.5$ \\
\hline Heart rate (beats/min) & $170 \pm 20$ & $141 \pm 22^{*}$ & $157 \pm 12$ & $158 \pm 11$ & $169 \pm 14$ & $174 \pm 21$ \\
\hline $\mathrm{pH}(\mathrm{U})$ & $7.36 \pm 0.05$ & $7.28 \pm 0.09 *$ & $7.29 \pm 0.05^{*}$ & $7.30 \pm 0.04$ & $7.32 \pm 0.04$ & $7.32 \pm 0.05$ \\
\hline $\mathrm{PaCO}_{2}$ (torr) & $52.5 \pm 4.5$ & $57.4 \pm 7.5$ & $56.6 \pm 2.9$ & $55.4 \pm 3.9$ & $54.8 \pm 3.9$ & $55.6 \pm 6.4$ \\
\hline $\mathrm{PaO}_{2}$ (torr) & $20.0 \pm 3.8$ & $17.7 \pm 3.0^{*}$ & $19.4 \pm 2.7$ & $18.8 \pm 3.2$ & $17.6 \pm 2.7$ & $18.60 \pm 4.0$ \\
\hline $\mathrm{SaO}_{2}(\%)$ & $44.1 \pm 11.4$ & $35.8 \pm 9.9^{*}$ & $39.8 \pm 9.4$ & $35.9 \pm 8.5$ & $33.6 \pm 9.5^{*}$ & $35.4 \pm 11.4$ \\
\hline
\end{tabular}

\footnotetext{
$* p \leq 0.005$ versus control.
} 
Table 2. Liffect of $L 60257$ on distribution of combined ventricular output /mon \pm .57$)(n=7) /$

Flow

Control

Adrenals
Spleen
Kidneys
I.ivert
Ciut
I.ower carcass
Brain
Upper carcass
Heart
I.ungs

$401 \pm 316$

$205 \pm 181$

$211 \pm 6.30$

$8.4 \pm 7.8$

$83 \pm 22$

$20 \pm 6$

$205 \pm 86$

20) \pm 6

$193 \pm 98$

$78 \pm 48$
Placenta
Combined ventricular
output

$198 \pm 42$

$462 \pm 77$

${ }^{*} p<0.05$ versus control.

t Hepatic artery flow.

60257 has been shown to inhibit leukotriene production from calcium ionophore-challenged rat peritoneal mononuclear cells and from human polymorphonuclear leukocytes as well as from antigen-sensitized chopped human lung (22-26). U 60257 also prevents the pulmonary hypertension induced by hypoxia in isolated perfused rat lungs (11) and intact newborn lambs (14) and prevents in a dose-dependent manner the bronchoconstriction and pulmonary function abnormalities in animal models of asthma (27-29). The high doses of U 60257 used in our study and others are necessary hecause of rapid plasma clearance of the compound $(22,24,27,28)$. The plasma half-life of $U 60257$ is only $15 \mathrm{~min}$ (27) and may be shorter in our preparation because of the possibility of placental clearance. I onger effects of $U 60257$ are seen after aerosol administration (27).

U 60257 may also have other effects on arachidonic acid metabolism. Al doses 50 times greater than those needed for leukotriene synthesis inhibition, 600257 is a competitive inhibitor of the activity of leukotrienes on guinea pig ileum (26). U 60)257 does not inhibit prostaglandin synthesis and actually increases thromboxane synthesis from rat peritoneal mononuclear cells (26). There are other interactions between the lipoxygenase and cyclooxygenase pathways. Leukotrienes also stimulate prostaglandin and thromboxane production. which, in turn. may mediate some of the physiologic effects $(8,30-32)$.

We were unable to measure leukotriene concentrations in biologic fluids from the fetal lambs and, therefore. we cannot absolutely confirm leukotriene synthesis inhibition by U 60)257 in these studies. However, the similarity in pulmonary vascular responses between $U$ 6()257, which inhibits leukotriene synthesis. and our previous studies with putative leukotriene receptor antagonists strongly support a role for active leukotriene production in maintenance of pulmonary vasoconstriction in the fetus. Reversal of the leukotriene effect by either mechanism would then lead to an increase in pulmonary blood flow.

The results of our study show that piriprost (U 60257), at putative inhibitor of leukotriene synthesis. increases pulmonary blood flow and decreases pulmonary vascular resistance in late gestation fetal lambs. The magnitude of these changes was similar to those caused by an intrapulmonary infusion of FPL 57231, a putative leukotriene receptor antagonist (3), and to those which occur with the onset of breathing at birth (1). These results support the hypothesis that leukotrienes play a role in maintaining the high pulmonary vascular resistance in late gestation fetal lambs.
Percentage of combined ventricular output

$\begin{array}{ccc}30 \mathrm{~min} & \begin{array}{c}\text { control } \\ \mathrm{ml} \cdot \mathrm{min}{ }^{1} \cdot 100 \mathrm{~g} \text { tissuc }\end{array} & 30 \mathrm{~min} \\ 488 \pm 187 & 0.1 .3 \pm 0.09 & \\ 199 \pm 146 & 0.51 \pm 0.29 & 0.14 \pm 0.07 \\ 176 \pm 54 & 2.53 \pm 0.26 & 1.46 \pm 0.34 \\ 10.4 \pm 5.5 & 0.41 \pm 0.38 & 0.4 \pm 0.62^{*} \\ 86 \pm 24 & 7.1 \pm 1.7 & 0.6 \pm 0.21 \\ 17 \pm 5 & 15.8 \pm 4.5 & 11.7 \pm 4.3^{*} \\ 164 \pm 66^{*} & 5.7 \pm 2.0 & 4.0 \pm 1.7^{*} \\ 17 \pm 6^{*} & 16.8 \pm 4.6 & 12.0 \pm 3.5^{*} \\ 26.3 \pm 162^{*} & 3.0 \pm 1.0 & 3.5 \pm 1.6 \\ 599 \pm 239^{*} & 5.3 \pm 4.81 & 26.8 \pm 10.2^{*}\end{array}$

$\mathrm{ml} \cdot \mathrm{min}^{1} \cdot \mathrm{kg}$ tissue $^{-1}$

$172 \pm 42 \quad 42.2 \pm 4.9$

$5.34 \pm 72$

1cknowledgments. The authors acknowledge Michael Bach. Ph.D., Upjohn (Company: Kalamazoo. MI for generously supplying piriprost. U 60257: Christine Roman and Trançoise Mauray for technical assistance: and Randall Kikukawa for editorial assistance.

\section{REFFRIVIIS}

1. Heymann MA logt Control of the pulmonary circulation in the perimatal peried. I Der Physiol $6: 281 \quad 39()$

2. I.ewis AB. Hermann MA. Rudolph $1 \mathrm{M}$ |976 (iestational changes in pulmomars ascular responses in tetal lambs in utero. (ire Res $39: 5305+1$

3. Soifer SJ. Loitz RI). Roman ( . Heymann MA 1985 l cukotriene end organ antagonists increase pulmonary hood llow in fital lambs. Am I Physiol $249: 11570-16576$

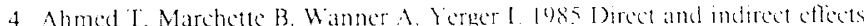
of leukotriene D $_{4}$ on the pulmonary and ststemic circulations. Am Rev Respir Dis $131.557-558$

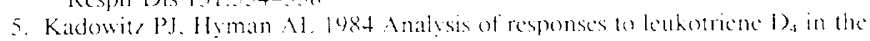
pulmonary vascular bed. ("irc Res $55: 707-717$

6. I eftler (W Mitchell JA Gren RS 1984 (ardiovascular effects of leuhotrienes in neonatal pigs: roke in hypoxic pulmonary vaseconstrictors. (ite Res $55: 780-787$

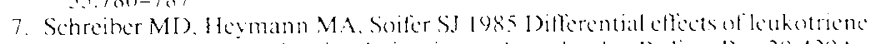
(I.T) (4and [)$_{4}$ on the circulation in newhorn lambs. Pediatr Re's $20: 429.1$

8. Yokochi K. OHey PM. Sideris F. Hamilton F. Huhtanen D). (oceani 1: 198.2 L eukotricne 1) a motent vasoconstrictor of the pulmonars and systemic circulations in the newborn lamb. In: Samuelsson $B$ and Paaletti $R$ (eds) circulations in the newhorn lamb. In: Samuelsson $B$ and Paolett $R$ (eds)
leukotrienes and ()ther L ipoxygenase Products. Raven Press. New Yorh. pl $211-214$

9. Ahmed T. Oliver W. Jr 1983 Does slow-reacting substance of anaphylaxis mediate hypoxic pulmonary basoconstriction. Am Rev Respir 1) is $127.566-$ 571

10). (ioldberg R.V. Sugiham (. Ahmed T. I) (ukdermus BI). Banios P. Setar IS. Bancalare $\mathrm{F}$. 1985 Influence of an antagenist of stow-reacting substance of anaphytaxis on the cardionalscular manifestations of hypoxia in piglets. Pediatr Res 19:1201-1205

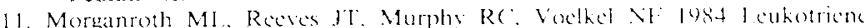
synthesis and receptor blockers block hypoxic pulmonary vasoconstriction. J Appl Physol $56: 1.340-1.346$

12. Morganroth MI. Stenmark KR. Zirrolli JA. Matudin R. Mathias M. Reces

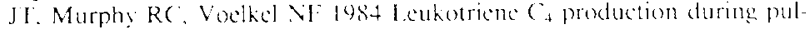
monary vasoconstriction in isolated rat lungs. Prostaglandins $6: 867-875$

13. Schreiber MI). Heymann MA. Soifer \$J 1985 I cukotriene inhibition prevents and reverses hypoxic pulmonary vasoconstriction in mewhorn lambs. Pediatr Res 19:437-441

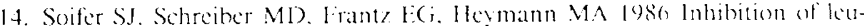
kotriene sunthesis attenuates hypoxia-induced pulmonary basoconstriction in newborn lambs. Pediatr Res 2():441 $\mathrm{A}$

15. Heymann MA. Payne BD. Hoffman JII: Rudolph AM 1977 Blond How measurements with radionuclide-labelled particles. Prog (ardionase 1) is $20: 55-70$

16. Rudolph $\triangle \mathrm{M}$ Heymann $\mathrm{MA}$ 1980 Methods for studving the circulation of the fetus in utero. In: Vathanicls Pla (ed) Animal Models in letal Medicine. 
Biomedical Press, Elsevier, North Holland, pp 1-57

17. Conover WJ 1980 Practical Nonparametric Statistics. Wilcy, New York, pp 299-308

18. Zar JH 1974 Biostatistical Analysis. Prentice-Hall, Englewood Cliffs, NJ, pp $124-127$

19. Heymann MA, Rudolph AM 1976 Effects of acetylsalicylic acid on the ductus arteriosus and circulation in fetal lambs in utero. Circ Res 38:418-422

20. Cohn HE, Sacks EJ, Heymann MA, Rudolph AM 1974 Cardjovascular responses to hypoxemia and acidemia in fetal lambs. Am J Obstet Gynecol 120:817-824

21. Iwamoto HS. Teitel DF. Rudolph AM 1986 Effects of birth events on regional blood flow. Pediatr Res 20:189A

22. Bach MK 1984 Prospects for the inhibition of leukotriene synthesis. Biochem Pharmacol 33:515-521

23. Bach MK, Bowman BJ, Brashler JR, Fitzpatrick FA. Griffin RL, Johnson HG, Major NJ. McGuire JC, McNee ML. Richards IM. Smith HW, Smith RJ, Speziale SC. Sun FF 1985 Piriprost: a selective inhibitor of leukotriene synthesis. In Hayaishi O, Yamamoto S (eds) Advances in Prostaglandin, Thromboxane, and Leukotriene Research, Vol 15. Raven Press, New York. pp 225-227

24. Bach MK. Brashler JR 1985 Studies with inhibitors of sulfidopeptide leukotriene synthesis. In: Lefer AM, McGee MH (eds) Progress in Clinical and Biological Research. Alan Russ. Inc., New York. pp 85-89

25. Bach MK. Brashler JR. Fitzpatrick FA, Griffin RL, Iden SS, Johnson HG McNee ML McGuire JC, Smith HW, Smith RJ. Sun FF, Wasserman MA
1983 In vivo and in vitro actions of a new selective inhibitor of leukotriene C and D synthesis. In: Samuelsson B, Paoletti R, Ramwell P (eds) Advances in Prostaglandin, Thromboxane, and Leukotriene Research, Vol 11. Raven Press, New York, pp 39-44

26. Bach MK, Brashler JR, Smith HW. Fitzpatrick FA Sun FF, McGuire JC 1982 6.9-deepoxy-6.9-(phenylimino)-delta ${ }^{6.8}$-prostaglandin $I_{1},(U-60,257)$, a new inhibitor of leukotriene C and D synthesis: in vitro studies. Prostaglandins 23:759-771

27. Johnson HG. McNee ML. Bach MR, Smith HW 1983 The activity of a new, novel inhibitor of leukotriene synthesis in Rhesus monkey Ascaris reactors. Int Arch Allergy Appl Immunol 70:169-173

28. Bach MK, Griffin RL, Richards IM 1985 Inhibition of the presumably leukotriene-dependent component of antigen-induced bronchoconstriction in the guinea pig by piriprost $(\mathrm{U}-60,257)$. Int Arch Allergy Appl Immunol 77:264266

29. Murlas C. Lee HK 1985 U-60.257 inhibits $\mathrm{O}_{3}$-induced bronchial hyperreactivity in the guinea pig. Prostaglandins 30:563-572

30. Kuehl FA Jr, Dougherty HW, Ham EA 1984 Interactions between prostaglandins and leukotrienes. Biochem Pharmacol 33:1-5

31. Mathé AA. Strandberg K. Yen S 1977 Prostaglandin release by slow reacting substance from guinea pig and human lung tissue. Prostaglandins 14:11051115

32. Samhoun MN, Piper PJ 1984 Actions and interactions of lipoxygenase and cyclo-oxygenase products in respiratory and vascular tissues. Prostaglandins Leukotrienes Med 13:79-87 